\title{
Associations of Skipping Breakfast, Lunch, and Dinner with Weight Gain and Overweight/Obesity in University Students: A Retrospective Cohort Study
}

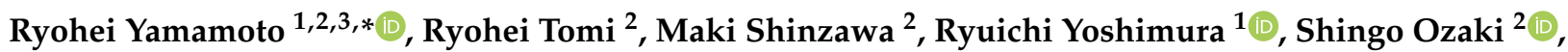 \\ Kaori Nakanishi ${ }^{1}$, Seiko Ide ${ }^{1}$, Izumi Nagatomo ${ }^{1}$, Makoto Nishida ${ }^{1}$, Keiko Yamauchi-Takihara ${ }^{1}$, Takashi Kudo ${ }^{1}$ \\ and Toshiki Moriyama ${ }^{1,2,3}$
}

1 Health and Counseling Center, Osaka University, 1-17 Machikaneyamacho, Toyonaka, Osaka 560-0043, Japan; ryoshimura@kid.med.osaka-u.ac.jp (R.Y.); k-nakanishi@wellness.hss.osaka-u.ac.jp (K.N.); ide@hacc.osaka-u.ac.jp (S.I.); iznagatomo@hacc.osaka-u.ac.jp (I.N.); mnishida@wellness.hss.osaka-u.ac.jp (M.N.); takihara@wellness.hss.osaka-u.ac.jp (K.Y.-T.); kudo@psy.med.osaka-u.ac.jp (T.K.); moriyama@wellness.hss.osaka-u.ac.jp (T.M.)

2 Department of Nephrology, Osaka University Graduate School of Medicine, 2-2-D11 Yamadaoka, Suita, Osaka 565-0871, Japan; rtomi@kid.med.osaka-u.ac.jp (R.T.); shinzawa@kid.med.osaka-u.ac.jp (M.S.); shingo.oz@kid.med.osaka-u.ac.jp (S.O.)

3 Health Promotion and Regulation, Department of Health Promotion Medicine, Osaka University Graduate School of Medicine, 1-17 Machikaneyamacho, Toyonaka, Osaka 560-0043, Japan * Correspondence: yamamoto@hacc.osaka-u.ac.jp; Tel.: +81-6-6850-6002

check for updates

Citation: Yamamoto, R.; Tomi, R.; Shinzawa, M.; Yoshimura, R.; Ozaki, S.; Nakanishi, K.; Ide, S.; Nagatomo, I.; Nishida, M.; Yamauchi-Takihara, K.; et al. Associations of Skipping Breakfast, Lunch, and Dinner with Weight Gain and Overweight/ Obesity in University Students: A Retrospective Cohort Study. Nutrients 2021, 13, 271. https://doi.org/ $10.3390 /$ nu13010271

Received: 10 December 2020

Accepted: 12 January 2021

Published: 19 January 2021

Publisher's Note: MDPI stays neutral with regard to jurisdictional claims in published maps and institutional affiliations.

Copyright: (c) 2021 by the authors. Licensee MDPI, Basel, Switzerland. This article is an open access article distributed under the terms and conditions of the Creative Commons Attribution (CC BY) license (https:// creativecommons.org/licenses/by/ $4.0 /)$.

\begin{abstract}
Although multiple studies have identified skipping breakfast as a risk factor for weight gain, there is limited evidence on the clinical impact of skipping lunch and dinner on weight gain. This retrospective cohort study including 17,573 male and 8860 female university students at a national university in Japan, assessed the association of the frequency of breakfast, lunch, and dinner with the incidence of weight gain $\left(\geq 10 \%\right.$ ) and overweight/obesity (body mass index $\geq 25 \mathrm{~kg} / \mathrm{m}^{2}$ ), using annual participant health checkup data. Within the observation period of $3.0 \pm 0.9$ years, the incidence of $\geq 10 \%$ weight gain was observed in $1896(10.8 \%)$ men and $1518(17.1 \%)$ women, respectively. Skipping dinner was identified as a significant predictor of weight gain in multivariableadjusted Poisson regression models for both men and women (skipping $\geq$ occasionally vs. eating every day, adjusted incidence rate ratios, 1.42 (95\% confidence interval: 1.02-1.98) and 1.67 (1.33-2.09) in male and female students, respectively), whereas skipping breakfast and lunch were not. Similarly, skipping dinner, not breakfast or lunch, was associated with overweight/obesity (1.74 (1.07-2.84) and $1.68(1.02-2.78)$ in men and women, respectively). In conclusion, skipping dinner predicted the incidence of weight gain and overweight/obesity in university students.
\end{abstract}

Keywords: meal frequency; breakfast skipping; lunch skipping; dinner skipping; weight gain; overweight/obesity; retrospective cohort study

\section{Introduction}

Obesity, defined as a disease resulting from excess body weight, is one of the major global health burdens, along with smoking, hypertension, and diabetes [1]. Obesity is a critical lifestyle factor that increases the risk of developing cardiometabolic diseases such as hypertension [1], diabetes [2], and cardiovascular disease (CVD) [3], and increases mortality [4]. Several studies suggest that prevention of obesity in the young population is crucial. Firstly, body mass index (BMI) at a younger age predicts the occurrence of obesity in adulthood [5]; secondly, there is a stronger association between obesity and mortality at a younger age than at an older age $[4,6]$. One of the potential outcomes is weight gain in first-year university students, often referred to as "Freshman 15" [7]. Ethnicity, sex, 
dietary behavior, and physical activity were identified as major predictors of weight gain in first-year university students [8].

One of the dietary risk factors for overweight/obesity is meal frequency [9]. Multiple observational studies have reported that low eating frequency is associated with overweight/obesity [10]. Among breakfast, lunch, and dinner, the association between breakfast frequency and overweight/obesity has been the most extensively studied. The Coronary Artery Risk Development in Young Adults (CARDIA) study reported an inverse dose-dependent association between breakfast frequency (0-3, 4-6, and 7 days/week) and the incidence of obesity (BMI $\geq 30 \mathrm{~kg} / \mathrm{m}^{2}$ ) in 3598 young adults [11]. A systematic review including 36 cross-sectional and 9 cohort studies verified that skipping breakfast increased the risk of overweight/obesity [12]. Few studies have reported the clinical impact of lunch and dinner frequency on overweight/obesity $[13,14]$, partly because a very low percentage of adults skip dinner [15].

The aim of this retrospective cohort study was to assess the clinical impact of skipping breakfast, lunch, and dinner on weight gain and overweight/obesity in 26,433 university students within their 6-year college life.

\section{Materials and Methods}

\subsection{Participants}

Over 30,144 university students enrolled at Osaka University, one of the largest national universities in Japan, between 2007 and 2015 who underwent baseline health checkup on admission at the Osaka University Healthcare Center in April or October were eligible for inclusion in this retrospective cohort study. We excluded $15(0.0 \%)$ students aged 17 years and 1062 students (3.5\%) with missing baseline data (Figure 1). Osaka University provides annual health checkups to university students and graduate students every April or October (Figure S1). After excluding 2634 (8.7\%) students who had no body weight measurements during the 6-year observation period, 26,433 (87.7\%) were included in the final analysis to assess the association between the frequency of breakfast, lunch, and dinner over the year preceding admission and weight gain after admission.

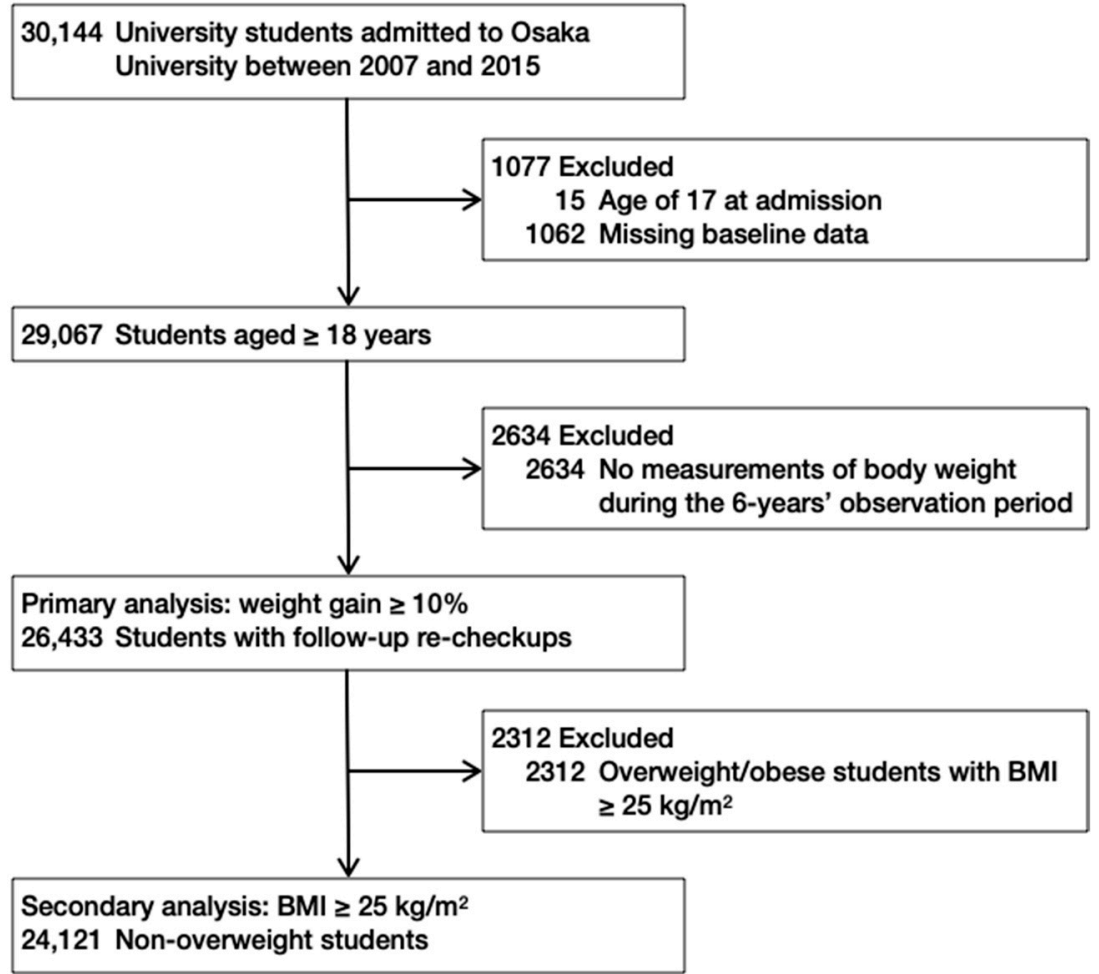

Figure 1. Flow diagram of inclusion and exclusion of study participants. BMI, body mass index. 
The study protocol was approved by the Ethics Committee of the Health and Counseling Center at Osaka University (No. 2020-7) and the Osaka University Hospital (No. 18352). Informed consent was not obtained from all the participants according to the Japanese Ethical Guidelines for Medical and Health Research Involving Human Subjects. All the data were retrieved from the electronic database of the Health and Counseling Center, Osaka University.

\subsection{Measurements}

The baseline health checkup variables at admission included age, BMI (body weight $(\mathrm{kg}) /$ height $\left.^{2}\left(\mathrm{~m}^{2}\right)\right)$, and questionnaires on meal frequency, dinner time, sleep duration on weekdays, smoking status, and drinking status. Questions related to these items were included in the general health questionnaires administered at the baseline health checkup. Breakfast, lunch, and dinner frequency were determined by asking the question "How often did you have breakfast/lunch/dinner over the past year?"; the possible responses were "Eating almost every day", "Skipping occasionally", "Skipping often", and "Usually skipping." Dinner time was determined by asking the question "What time did you have dinner?"; the four possible answers were as follows: "Before 7 PM", "7-9 PM", "9-11 PM", and "After 11 PM." Sleep duration on weekdays was determined by asking the question "How long do you sleep on weekdays?"; the possible answers were "< 5 h", " $5-6 h$ ", "6-7 h", "7-8 h", and " $\geq 8$ h." Smoking status was determined by asking the question "Do you smoke?"; the possible answers were "I do not smoke", "I quitted smoking", "I would like to quit smoking", and "I smoke." Drinking status was determined by asking the question "Do you drink alcohol?"; the possible answers were "I do not drink", "I drink occasionally", "I drink 1 day/week”, ,I drink 2-3 days/week", and "I drink $\geq 4$ days/week."

The outcome measures of the present study were weight gain $\geq 10 \%$ [16] in all students and overweight/obesity (BMI $\geq 25 \mathrm{~kg} / \mathrm{m}^{2}$ ) [17] in students with a BMI of $<25 \mathrm{~kg} / \mathrm{m}^{2}$. Observational time was defined as the period from the health checkup at admission to (i) the incidence of each outcome or (ii) the last body weight measurement at the annual Osaka University health checkups within 6 years (=2192 days) of the baseline checkup before April 2019, whichever came first.

To assess the degree to which the baseline dinner frequencies reflected the dinner frequency during the observation period, the answers to "How often did you have dinner during the past year?" at the annual health checkups for university students 1 year (365 days) and 3 years (1095 days) after the baseline checkup, with a window period of \pm 182 days, were retrieved.

\subsection{Statistical Analysis}

Because of the small number of students skipping dinner often (men, $\mathrm{n}=20(0.1 \%)$; women, $\mathrm{n}=32(0.4 \%)$ ) and usually (men, $\mathrm{n}=4(0.0 \%)$; women, $\mathrm{n}=11(0.1 \%))$, dinner frequency was divided into two groups: eating every day and skipping dinner $\geq$ occasionally. Similarly, students skipping lunch often (men, $\mathrm{n}=76(0.4 \%)$; women, $\mathrm{n}=20(0.2 \%)$ ), and usually (men, $\mathrm{n}=21(0.1 \%)$; women, $\mathrm{n}=7(0.1 \%)$ ) were categorized as skipping lunch $\geq$ occasionally. Breakfast frequency was classified as eating every day, skipping occasionally, and skipping $\geq$ often, including skipping often (men, $\mathrm{n}=663(3.8 \%)$; women, $\mathrm{n}=209(2.4 \%)$ ) and usually (men, $\mathrm{n}=402(2.3 \%)$; women, $\mathrm{n}=76(0.9 \%))$. Because 17,476 (99.4\%) men and 8847 (99.9\%) women answered "I do not smoke", subjects were categorized into non-smokers with "I do not smoke" and smokers with other answers. Drinking status was classified into two categories: non-drinkers who answered "I do not drink" (men, $\mathrm{n}=15,915(90.6 \%)$; women, $\mathrm{n}=8442(95.3 \%)$ ) and drinkers who answered "I drink occasionally" (men, $\mathrm{n}=1377$ (7.8\%); women, $\mathrm{n}=378(4.3 \%)$ ), "I drink 1 day/week" (men, $\mathrm{n}=128(0.7 \%) ;$ women, $\mathrm{n}=21(0.2 \%)$ ), "I drink $2-3$ day/week" (men, $\mathrm{n}=127(0.7 \%)$; women, $\mathrm{n}=16(0.2 \%))$, and "I drink $\geq 4$ days /week" (men, $\mathrm{n}=26(0.1 \%)$; women, $\mathrm{n}=3(0.0 \%))$. The clinical characteristics of the different meal frequency categories 
were compared using the Student's t-test, analysis of variance, and the chi-squared test, as appropriate.

The cumulative probability of the incidence of weight gain $\geq 10 \%$ and BMI $\geq 25 \mathrm{~kg} / \mathrm{m}^{2}$ was calculated using the Kaplan-Meier method and compared using the log-rank test among the categories of meal frequency. To assess the association between the baseline meal frequency and the incidence of each outcome, unadjusted and multivariable-adjusted incidence rate ratios (IRR) with the corresponding 95\% confidence interval (CI) of each meal frequency category were calculated using Poisson regression models. Model 1 was an unadjusted model including frequency of each meal as an independent variable. In model 2, the association between frequency of each meal and the outcomes were assessed after adjusting for admission year (2007, 2008, 2009, 2010, 2011, 2012, 2013, 2014, and $2015)$, age $\left(18,19,20\right.$, and $\geq 21$ years), BMI $\left(\mathrm{kg} / \mathrm{m}^{2}\right)$, smoking status (non-smokers and smokers), drinking status (non-drinkers and drinkers), sleep duration [18] on weekdays $(<5,5-6,6-7,7-8$, and $\geq 8 \mathrm{~h})$, and dinner time [19] (before 7 PM, 7-9 PM, 9-11 PM, and after $11 \mathrm{PM}$ ). Model 3 assessed the independent associations between breakfast, lunch, and dinner frequency with the outcomes after adjusting for each other. Robust (HuberWhite) sandwich-based standard errors were used to validate inferences for estimates in Poisson regression models. Appropriateness of Poisson regression models was tested with a goodness-of-fit test using the deviance statistic.

To evaluate an association between the baseline dinner frequency and the dinner frequency during the observation period, reproducibility of the baseline dinner frequency with the dinner frequency 1 and 3 years after admission was assessed using the Gwet's AC1 coefficient, which was calculated using Stata's kappaetc command [20]. Reproducibility with Gwet's AC1 coefficients of $<0.00,0.00-0.20,0.21-0.40,0.41-0.60,0.61-0.80$, or $0.81-1.00$ was regarded as poor, slight, fair, moderate, substantial, or almost perfect, respectively [21].

To identify the characteristics of students who kept skipping dinner $\geq$ occasionally, the baseline characteristics were compared between students who kept skipping dinner $\geq$ occasionally at admission and 1 year after admission and those who skipped dinner $\geq$ occasionally at admission but ate dinner every day 1 year after admission using the Student's t-test and the chi-squared test.

Continuous variables were expressed as the mean \pm standard deviation, while categorical variables were expressed as numbers and proportions. A $p$ value $<0.05$ was considered significant. All statistical analyses were performed using Stata version 16.1 (Stata Corp, College Station, TX, USA).

\section{Results}

Baseline characteristics of 17,573 male students are listed in Table 1. Compared with the 17,307 (98.5\%) male students who ate dinner every day, those who skipped dinner $\geq$ occasionally $(n=266(1.5 \%)$ ) were likely to be older and more overweight, have shorter sleep duration and higher prevalence of smokers and drinkers, skip other meals more frequently, and eat dinner later $(p<0.05)$. With regard to the frequency of breakfast and lunch frequency, similar trends were observed in male students $(p<0.05)$, except for BMI (Tables S1 and S2). Of the 8860 female students, those who skipped dinner $\geq$ occasionally ( $\mathrm{n}=35894.0 \%)$ ), were likely to be older and more overweight, have shorter sleep duration and higher prevalence of smokers and drinkers, and skip other meals more frequently than the $8502(96.0 \%)$ female students who ate dinner every day $(p<0.05)$ (Table 2). Female students who skipped breakfast and lunch were likely to be older, have longer sleep duration and higher prevalence of drinkers, skip other meals, and eat dinner later than those who ate breakfast and lunch every day $(p<0.05)$ (Tables S3 and S4). 
Table 1. Baseline characteristics, observation period, and outcome incidences of 17,573 male students stratified by dinner frequency.

\begin{tabular}{|c|c|c|c|c|}
\hline Dinner frequency & All & $\begin{array}{c}\text { Eating } \\
\text { Every Day }\end{array}$ & $\begin{array}{c}\text { Skipping } \\
\geq \text { Occasionally }\end{array}$ & $p$ \\
\hline Number & 17,573 & 17,307 & 266 & \\
\hline \multicolumn{5}{|l|}{ Baseline characteristics at admission } \\
\hline Age, 18 years, n (\%) & $11,342(64.5)$ & $11,228(64.9)$ & $114(42.9)$ & $<0.001$ \\
\hline 19 & $5625(32.0)$ & $5508(31.8)$ & $117(44.0)$ & \\
\hline 20 & $387(2.2)$ & $367(2.1)$ & $20(7.5)$ & \\
\hline $21-60$ & $219(1.2)$ & $204(1.2)$ & $15(5.6)$ & \\
\hline Height $(\mathrm{cm})$ & $171.3 \pm 5.7$ & $171.3 \pm 5.7$ & $171.2 \pm 5.6$ & 0.763 \\
\hline Body weight, $\mathrm{kg}$ & $63.4 \pm 9.4$ & $63.3 \pm 9.3$ & $67.1 \pm 12.8$ & $<0.001$ \\
\hline BMI, $\mathrm{kg} / \mathrm{m}^{2}$ & $21.6 \pm 2.9$ & $21.6 \pm 2.9$ & $22.9 \pm 4.1$ & $<0.001$ \\
\hline$<25.0 \mathrm{~kg} / \mathrm{m}^{2}, \mathrm{n}(\%)$ & $15,656(89.1)$ & $15,450(89.3)$ & $206(77.4)$ & $<0.001$ \\
\hline$\geq 25.0$ & $1917(10.9)$ & $1857(10.7)$ & $60(22.6)$ & \\
\hline Smokers, n (\%) & $97(0.6)$ & $84(0.5)$ & $13(4.9)$ & $<0.001$ \\
\hline Drinkers, n (\%) & $1658(9.4)$ & $1596(9.2)$ & $62(23.3)$ & $<0.001$ \\
\hline Sleep duration, <5 h, n (\%) & $547(3.1)$ & $532(3.1)$ & $15(5.6)$ & $<0.001$ \\
\hline $5-6$ & $5604(31.9)$ & $5494(31.7)$ & $110(41.4)$ & \\
\hline $6-7$ & $8473(48.2)$ & $8375(48.4)$ & $98(36.8)$ & \\
\hline $7-8$ & $2521(14.3)$ & $2485(14.4)$ & $36(13.5)$ & \\
\hline$\geq 8$ & $428(2.4)$ & $421(2.4)$ & $7(2.6)$ & \\
\hline Breakfast, eating every day, $\mathrm{n}(\%)$ & $14,233(81.0)$ & $14,115(81.6)$ & $118(44.4)$ & $<0.001$ \\
\hline Skipping occasionally & $2275(12.9)$ & $2170(12.5)$ & 105 (39.5) & \\
\hline Skipping $\geq$ often & $1065(6.1)$ & $1022(5.9)$ & $43(16.2)$ & $<0.001$ \\
\hline Lunch, eating every day, n (\%) & $16,448(93.6)$ & $16,327(94.3)$ & $121(45.5)$ & $<0.001$ \\
\hline Skipping $\geq$ occasionally & $1125(6.4)$ & $980(5.7)$ & $145(54.5)$ & \\
\hline Dinner time, before 7 PM, n (\%) & 3255 (18.5) & $3201(18.5)$ & $54(20.3)$ & $<0.001$ \\
\hline 7-9 PM & $11,453(65.2)$ & $11,310(65.3)$ & $143(53.8)$ & \\
\hline 9-11 PM & $2681(15.3)$ & $2624(15.2)$ & $57(21.4)$ & \\
\hline After 11 PM & $184(1.0)$ & $172(1.0)$ & $12(4.5)$ & \\
\hline \multicolumn{5}{|c|}{ Observation period and outcome incidences } \\
\hline Observation period (years) & $3.0 \pm 0.9$ & $3.0 \pm 0.9$ & $3.0 \pm 1.0$ & 0.704 \\
\hline Weight gain $\geq 10 \%$, n (\%) & $1896(10.8)$ & $1857(10.7)$ & $39(14.7)$ & 0.040 \\
\hline IR per $1000 \mathrm{PY}(95 \% \mathrm{CI})$ & $36.1(34.5,37.8)$ & $35.9(34.3,37.6)$ & $49.4(36.1,67.6)$ & \\
\hline $\mathrm{BMI} \geq 25 \mathrm{~kg} / \mathrm{m}^{2}, \mathrm{n}(\%)$ & $671(4.3)$ & $653(4.2)$ & $18(8.7)$ & 0.001 \\
\hline IR per 1000 PY $(95 \%$ CI $)$ & $14.1(13.1,15.2)$ & $13.9(12.9,15.0)$ & $29.0(18.3,46.0)$ & \\
\hline
\end{tabular}

Mean \pm standard deviation; BMI, body mass index; CI, confidence interval, IR, incidence rate; PY, person-year.

During the observation period of $3.0 \pm 0.9$ years, the incidence of $\geq 10 \%$ weight gain was observed in $1857(10.7 \%)$ and $39(14.7 \%)$ male students who ate dinner every day and skipped dinner $\geq$ occasionally, respectively $(p=0.040)$ (Table 1$)$. Male students skipping dinner $\geq$ occasionally were likely to have a higher cumulative probability of weight gain than those eating dinner every day, although the difference between these groups was at a marginally significant level ( $p=0.059$ ) (Figure 2a). Considering breakfast frequency, male students skipping breakfast $\geq$ often had a higher risk of $\geq 10 \%$ weight gain than those eating breakfast every day and skipping breakfast occasionally $(p=0.029)$ (Figure S2a). By contrast, no significant difference was observed between male students eating lunch every day and those skipping lunch $\geq$ occasionally $(p=0.222)$ (Figure S3a). Unadjusted Poisson regression models showed that dinner frequency (IRR ( $95 \% \mathrm{CI}$ ) of skipping $\geq$ occasionally vs. eating every day: 1.38 (1.01-1.87)) and breakfast frequency (IRR (95\% CI) of eating every day, skipping occasionally, and skipping $\geq$ often: 1.00 (reference), 1.02 (0.89-1.16), and 1.29 (1.10-1.52), respectively) were significantly associated with $\geq 10 \%$ weight gain, while there was no association between lunch frequency and $\geq 10 \%$ weight gain (IRR (95\% CI) of skipping $\geq$ occasionally vs. eating every day: $1.14(0.97,1.35)$ ) (Figure 3a, Model 1). Even after multivariable adjustment for clinically relevant factors, male students skipping dinner $\geq$ occasionally (1.42 (1.02-1.98)) were at a higher risk of $\geq 10 \%$ weight 
gain than those eating dinner, whereas those skipping breakfast were not (1.00 (reference), 0.97 (0.85-1.11), and 1.18 (0.99-1.40), respectively) (Figure 3a, Model 3).

Table 2. Baseline characteristics, observation period, and outcome incidences of 8860 female students stratified by dinner frequency.

\begin{tabular}{|c|c|c|c|c|}
\hline Dinner frequency & All & $\begin{array}{c}\text { Eating } \\
\text { Every Day }\end{array}$ & $\begin{array}{c}\text { Skipping } \\
\geq \text { Occasionally }\end{array}$ & $p$ \\
\hline Number & 8860 & 8502 & 358 & \\
\hline \multicolumn{5}{|l|}{ Baseline characteristics at admission } \\
\hline Age, 18 years, n (\%) & $6537(73.8)$ & $6336(74.5)$ & $201(56.1)$ & $<0.001$ \\
\hline 19 & $2052(23.2)$ & $1926(22.7)$ & $126(35.2)$ & \\
\hline 20 & $160(1.8)$ & $145(1.7)$ & $15(4.2)$ & \\
\hline $21-60$ & $111(1.3)$ & $95(1.1)$ & $16(4.5)$ & \\
\hline Height, $\mathrm{cm}$ & $158.4 \pm 5.2$ & $158.4 \pm 5.2$ & $158.7 \pm 5.1$ & 0.250 \\
\hline Body weight, kg & $51.5 \pm 6.8$ & $51.4 \pm 6.8$ & $53.1 \pm 7.0$ & $<0.001$ \\
\hline BMI, $\mathrm{kg} / \mathrm{m}^{2}$ & $20.5 \pm 2.4$ & $20.5 \pm 2.4$ & $21.1 \pm 2.4$ & $<0.001$ \\
\hline$<25.0 \mathrm{~kg} / \mathrm{m}^{2}, \mathrm{n}(\%)$ & $8465(95.5)$ & $8134(95.7)$ & $331(92.5)$ & 0.004 \\
\hline$\geq 25.0$ & $395(4.5)$ & $368(4.3)$ & $27(7.5)$ & \\
\hline Smokers, n (\%) & $13(0.1)$ & $11(0.1)$ & $2(0.6)$ & 0.038 \\
\hline Drinkers, $\mathrm{n}(\%)$ & $418(4.7)$ & $367(4.3)$ & $51(14.2)$ & $<0.001$ \\
\hline Sleep duration, $<5$ h, n (\%) & $264(3.0)$ & $246(2.9)$ & $18(5.0)$ & 0.003 \\
\hline 5-6 & 3159 (35.7) & $3018(35.5)$ & $141(39.4)$ & \\
\hline $6-7$ & 4209 (47.5) & $4070(47.9)$ & $139(38.8)$ & \\
\hline $7-8$ & 1109 (12.5) & $1057(12.4)$ & $52(14.5)$ & \\
\hline$\geq 8$ & $119(1.3)$ & $111(1.3)$ & $8(2.2)$ & \\
\hline Breakfast, eating every day, n (\%) & $7793(88.0)$ & $7538(88.7)$ & $255(71.2)$ & $<0.001$ \\
\hline Skipping occasionally & $782(8.8)$ & $707(8.3)$ & $75(20.9)$ & \\
\hline Skipping $\geq$ often & $285(3.2)$ & $257(3.0)$ & $28(7.8)$ & \\
\hline Lunch, eating every day, n (\%) & $8451(95.4)$ & $8178(96.2)$ & $273(76.3)$ & $<0.001$ \\
\hline Skipping $\geq$ occasionally & $409(4.6)$ & $324(3.8)$ & $85(23.7)$ & \\
\hline Dinner time, before 7 PM, n (\%) & $2288(25.8)$ & $2185(25.7)$ & $103(28.8)$ & 0.111 \\
\hline 7-9 PM & $5611(63.3)$ & $5405(63.6)$ & $206(57.5)$ & \\
\hline 9-11 PM & $920(10.4)$ & $873(10.3)$ & $47(13.1)$ & \\
\hline After 11 PM & $41(0.5)$ & $39(0.5)$ & $2(0.6)$ & \\
\hline \multicolumn{5}{|c|}{ Observation period and incidence of outcomes } \\
\hline Observation period (years) & $2.9 \pm 1.0$ & $2.9 \pm 1.0$ & $2.8 \pm 1.1$ & 0.708 \\
\hline Weight gain $\geq 10 \%$, n (\%) & $1518(17.1)$ & $1436(16.9)$ & $82(22.9)$ & 0.041 \\
\hline IR per $1000 \mathrm{PY}(95 \% \mathrm{CI})$ & $58.1(55.3,61.1)$ & $57.2(54.3,60.2)$ & $80.3(64.7,99.7)$ & \\
\hline $\mathrm{BMI} \geq 25 \mathrm{~kg} / \mathrm{m}^{2}, \mathrm{n}(\%)$ & $266(3.1)$ & $248(3.0)$ & $18(5.4)$ & 0.015 \\
\hline IR per 1000 PY (95\% CI) & $10.0(8.9,11.3)$ & $9.7(8.6,11.0)$ & $17.8(11.2,28.2)$ & \\
\hline
\end{tabular}

Mean \pm standard deviation; BMI, body mass index; CI, confidence interval, IR, incidence rate; PY, person-year.

Of the 8502 female students eating dinner every day and the 358 female students skipping dinner $\geq$ occasionally, $\geq 10 \%$ weight gain was observed in $1436(16.9 \%)$ and $82(22.9 \%)$ students, respectively (Table 2). The cumulative probability of the incidence of $\geq 10 \%$ weight gain was significantly higher in the female students skipping dinner $\geq$ occasionally than in those eating every day $(p=0.002)$ (Figure $2 b)$; by contrast, no significant difference was observed in breakfast $(p=0.464)$ (Figure S2b) and lunch frequencies $(p=0.677)$ (Figure S3b). In unadjusted Poisson regression models, dinner frequency was significantly associated with $\geq 10 \%$ weight gain $(1.40(1.13-1.75))$, whereas breakfast frequency $(1.00$ (reference), $1.06(0.89-1.26)$, and $0.87(0.64-1.18))$ or lunch frequency $(0.95(0.75-1.21))$ were not associated with $\geq 10 \%$ weight gain (Figure $3 b$, Model 1 ). Multivariable-adjusted models showed a significant association between dinner frequency and $\geq 10 \%$ weight gain $(1.67$ (1.33-2.09)); however, breakfast frequency (1.00 (reference), $0.98(0.82,1.17)$, and $0.84(0.62$, $1.13)$ ) and lunch frequency $(0.93(0.72-1.20))$ were not associated with $\geq 10 \%$ weight gain (Figure 3b, Model 3). 
a. Weight gain $\geq 10 \%$ in 17,573 male students

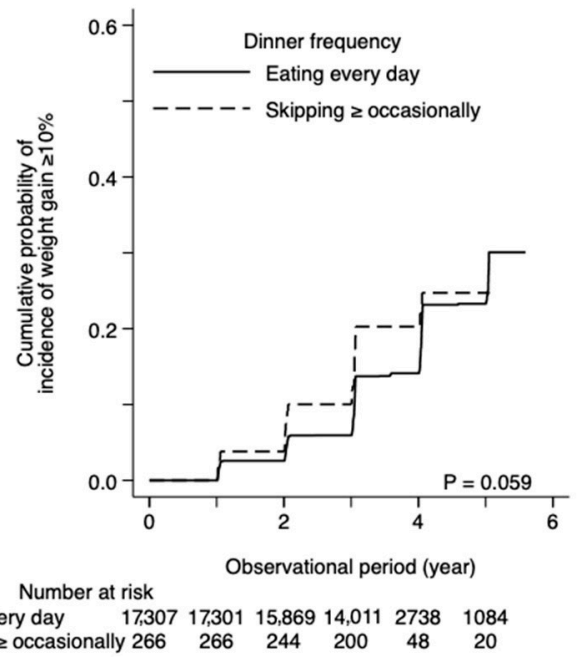

c. $B M I \geq 25 \mathrm{~kg} / \mathrm{m}^{2}$ in 15,656 male students

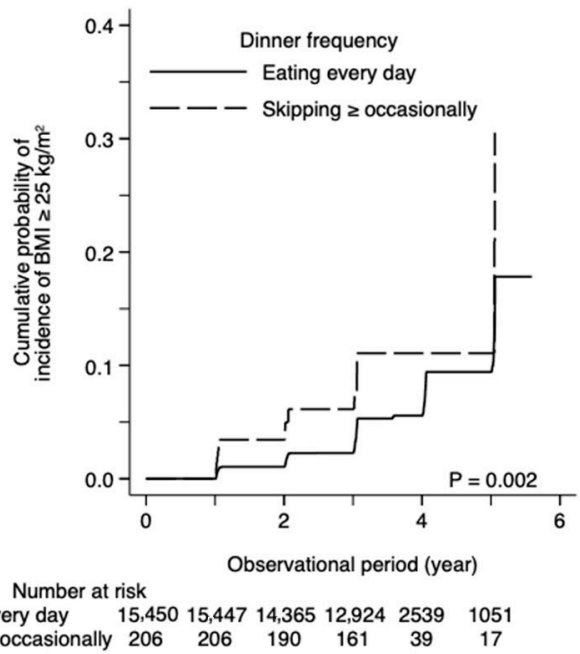

b. Weight gain $\geq 10 \%$ in 8860 female students

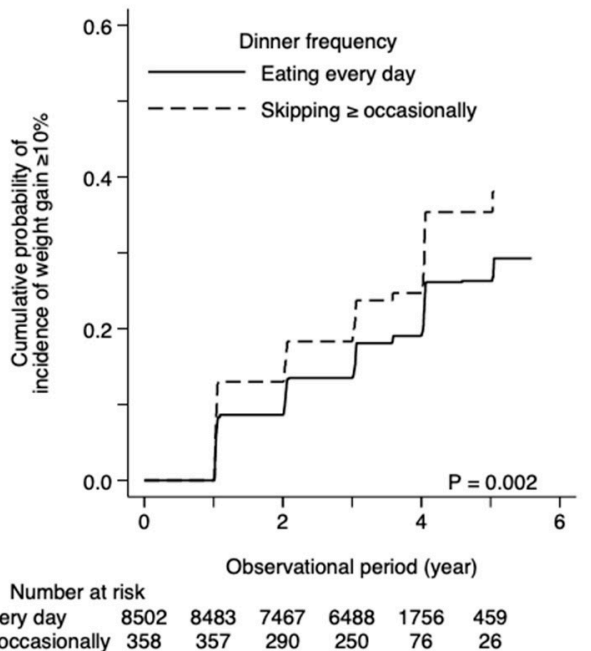

d. $\mathrm{BMl} \geq 25 \mathrm{~kg} / \mathrm{m}^{2}$ in 8465 female students

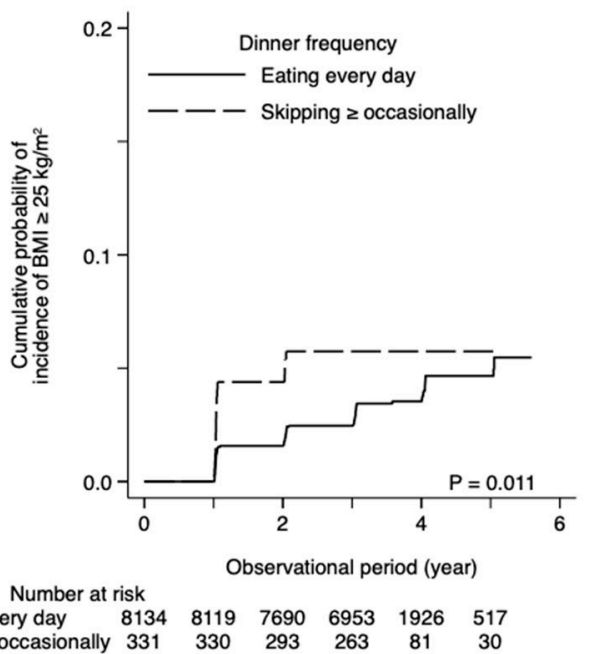

Figure 2. Dinner frequency and the cumulative probabilities of the incidence of $\geq 10 \%$ weight gain (a,b) and $\mathrm{BMI} \geq 25 \mathrm{~kg} / \mathrm{m}^{2}(\mathbf{c}, \mathbf{d})$ in male $(\mathbf{a}, \mathbf{c})$ and female $(\mathbf{b}, \mathbf{d})$ students. BMI, body mass index.

After excluding 1917 (10.9\%) male and 395 (4.5\%) female students with BMI $\geq 25 \mathrm{~kg} / \mathrm{m}^{2}$, we assessed the association between meal frequency and the incidence of overweight/obesity $\left(B M I \geq 25 \mathrm{~kg} / \mathrm{m}^{2}\right)$ in students with a BMI of $<25 \mathrm{~kg} / \mathrm{m}^{2}$. The cumulative probability of male and female students skipping dinner $\geq$ occasionally was significantly higher than of those eating dinner every day ( $p=0.002$ and 0.011 in male and female students, respectively) (Figure 2c,d). No significant association was observed between breakfast and lunch frequency in male students ( $p=0.569$ and 0.187 for breakfast and lunch frequency, respectively) (Figures S2c and S3c) and female students ( $p=0.154$ and 0.201 , respectively) (Figures S2d and S3d). In multivariate-adjusted Poisson regression models, dinner frequency was identified as a significant predictor of $\mathrm{BMI} \geq 25 \mathrm{~kg} / \mathrm{m}^{2}$ (male students, 1.74 (1.07-2.84); female students, 1.68 (1.02-2.78)), while breakfast and lunch frequencies were not (Figure 3c,d, Model 3). 

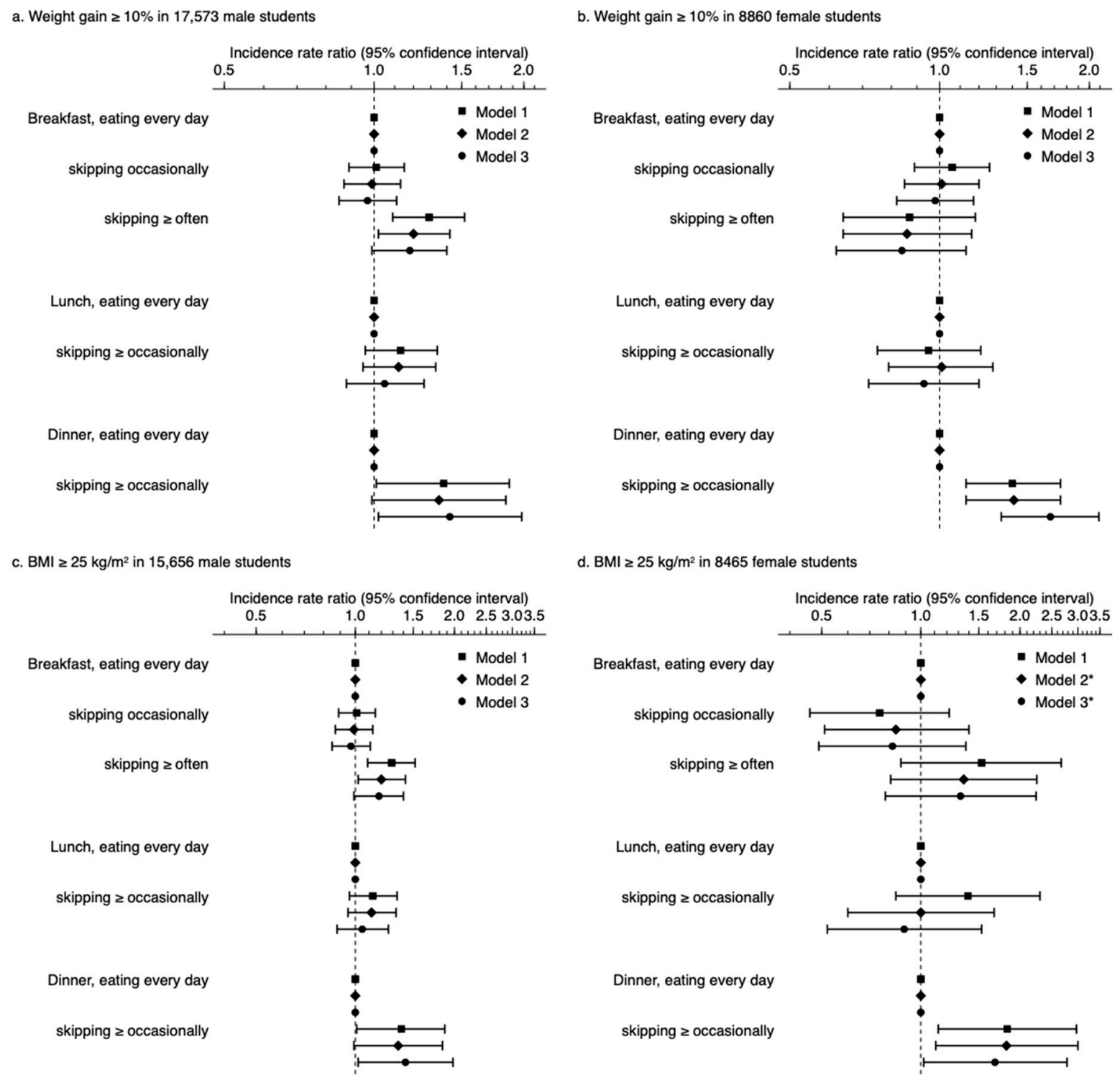

d. $B M I \geq 25 \mathrm{~kg} / \mathrm{m}^{2}$ in 8465 female students

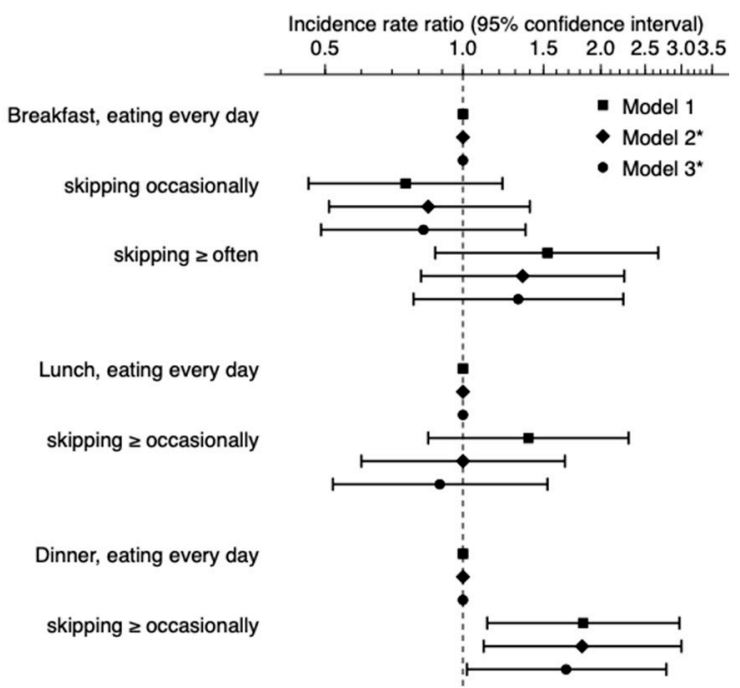

Figure 3. Meal frequency and incidence of $\geq 10 \%$ weight gain $(\mathbf{a}, \mathbf{b})$ and body mass index (BMI) $\geq 25 \mathrm{~kg} / \mathrm{m}^{2}(\mathbf{c}, \mathbf{d})$. BMI, body mass index. Model 1, unadjusted. Model 2, adjusted for admission year (2007, 2008, 2009, 2010, 2011, 2012, 2013, 2014, and 2015), age $\left(18,19,20\right.$, and $\geq 21$ years), BMI $\left(\mathrm{kg} / \mathrm{m}^{2}\right)$, smoking status (non-smokers and smokers), drinking status (non-drinkers and drinkers), dinner time (before 7 PM, 7-9 PM, 9-11 PM, and after 11 PM), and sleep duration on weekdays $(<5,5-6,6-7,7-8$, and $\geq 8 \mathrm{~h})$. Model 3, adjusted for covariates in model 2 and frequencies of breakfast, lunch, and dinner (e.g., breakfast frequency was adjusted for lunch and dinner frequencies). ${ }^{*}$ Not adjusted for smokers because of no incidence of the outcome in smokers $(n=13)$.

To assess how strongly baseline dinner frequency reflected dinner frequency during the observation period, dinner frequency 1 and 3 years after admission was assessed (Figure 4). Of the 17,307 male students with baseline dinner frequency of eating every day, $13,436(77.6 \%)$ and $12,709(73.4 \%)$ students answered to the question of dinner frequency at their annual health checkups 1 and 3 years after admission, respectively. The vast majority of them kept eating dinner every day 1 and 3 years after admission $(96.3 \%$ and $96.5 \%$, respectively). Of the 266 male students with baseline dinner frequency of skipping $\geq$ occasionally, $212(79.7 \%)$ and $176(66.2 \%)$ gave answers at their annual health checkups 1 and 3 years after admission. Their proportion of skipping dinner $\geq$ occasionally 1 and 3 years after admission was $22.6 \%$ and $16.5 \%$, which was substantially higher than that of the male students with baseline dinner frequency of eating every day $(3.7 \%$ and $3.5 \%$ ). The Gwet's AC1 coefficient suggested almost perfect reproducibility of dinner 
frequency 1 and 3 years after submission in male students (Gwet's AC1 coefficient 1 and 3 years after admission $=0.950$ and 0.952 , respectively). Similarly, almost perfect reproducibility was observed in female students (Gwet's AC1 coefficient 1 and 3 years after admission $=0.886$ and 0.908 ). In the female students with baseline dinner frequency of eating every day, the proportion of skipping dinner $\geq$ occasionally 1 and 3 years after admission was $8.1 \%$ and $5.8 \%$, whereas that was $40.4 \%$ and $26.7 \%$ in those with the baseline dinner frequency of skipping $\geq$ occasionally.

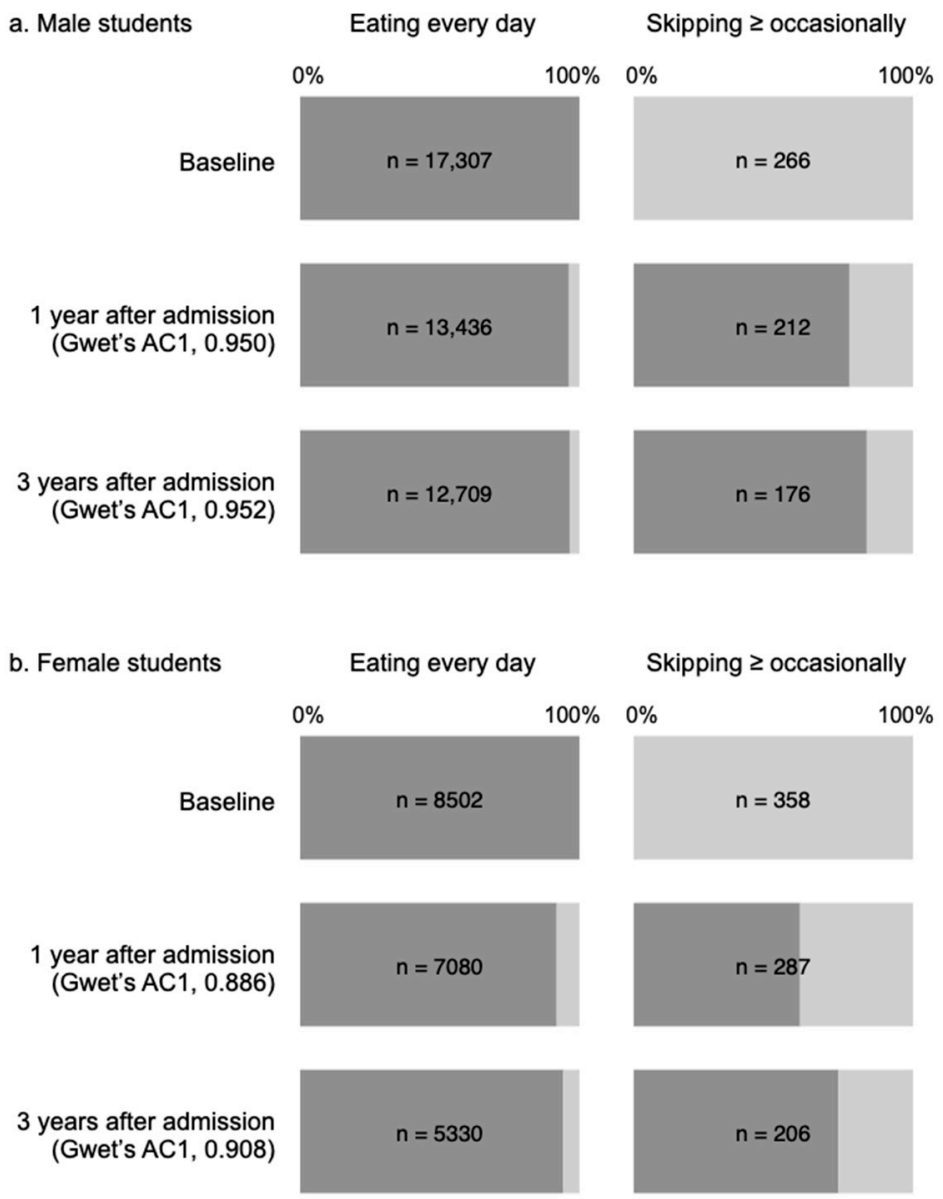

Figure 4. Baseline dinner frequency and dinner frequency 1 and 3 years after admission in male (a) and (b) female students. Dark and pale gray bars indicate the proportion of eating dinner every day and skipping dinner $\geq$ occasionally, respectively. In both male and female students, baseline dinner frequency reflected dinner frequency 1 and 3 years after admission almost perfectly (Gwet's AC1 coefficient $>0.8$ ).

To characterize the students who keep dinner frequency of skipping $\geq$ occasionally within 1 year of the observation period, baseline characteristics were compared between the 48 male students who kept skipping dinner $\geq$ occasionally at admission and 1 year after admission and the 164 male students who skipped dinner $\geq$ occasionally at admission but ate dinner every day 1 year after admission (Table S5). The male students who kept skipping dinner $\geq$ occasionally had a higher level of body weight and BMI and higher prevalence of smokers $(p<0.05)$. In contrast, no significant difference was observed between the 116 female students who kept skipping dinner $\geq$ occasionally and the 171 female students who skipped dinner $\geq$ occasionally at admission but ate dinner every day 1 year after admission (Table S6). 


\section{Discussion}

This retrospective large cohort study revealed that skipping dinner was significantly associated with $\geq 10 \%$ weight gain and overweight/obesity (BMI $\geq 25 \mathrm{~kg} / \mathrm{m}^{2}$ ) in both male and female students. These results suggest that skipping dinner, which was much less prevalent than skipping breakfast, has a stronger association with weight gain and overweight/obesity than skipping breakfast. The strengths of the present study are as follows: cohort study design with the mean observation period of 3 years; large sample size, which allowed the assessment of the clinical impact of low prevalence of skipping dinner; and two outcomes ( $\geq 10 \%$ weight gain and BMI $\left.\geq 25 \mathrm{~kg} / \mathrm{m}^{2}\right)$.

Few studies have previously reported the association between skipping dinner and overweight/obesity. An Iranian cross-sectional study, the Childhood and Adolescence Surveillance and Prevention of Adult Non-communicable Disease (CASPIAN-III) study, including 5642 school students aged 10-18 years reported that students who skipped dinner had a significantly high prevalence of overweight/obesity [14]. A Spanish cross-sectional study including 16,929 men and 18,045 women aged 25-64 years showed that women who skipped dinner had a significantly higher prevalence of obesity (BMI $\geq 30 \mathrm{~kg} / \mathrm{m}^{2}$ ), while there was no increased prevalence of obesity among the men who skipped dinner [13]. This retrospective cohort study demonstrated that skipping dinner predicted the incidence of weight gain and overweight/obesity in both the 17,573 male and the 8860 female university students. This is consistent with a 1946 British birth cohort including 1416 young adults aged 36 years reporting a dose-dependent association between the irregularity of energy intake at dinner at the age of 36 years and overweight/obesity at the age of 53 years [22]. Compared to the students who ate dinner every day, those with lower frequency of dinner were considered to have higher irregularity of energy intake at dinner. Therefore, this dosedependent association strongly suggested that skipping dinner predicted the incidence of overweight/obesity. Although the 1946 British birth cohort also showed a significant dose-dependent association between the irregularity of energy intake at breakfast at the age of 36 years and overweight/obesity at the age of 53 years, irregularities of energy intake at breakfast and dinner were not included in the single multivariable logistic regression model; therefore, whether breakfast and dinner were independently associated with overweight/obesity remained unknown. The present study clarified that skipping dinner was independently associated with $\geq 10 \%$ weight gain and overweight/obesity in both male and female students, while skipping breakfast was not, suggesting a greater clinical impact of dinner on weight gain compared with breakfast.

One of the plausible mechanisms for the association between skipping dinner and weight gain may be an excess of energy intake due to upregulation of appetite after skipping dinner, leading to high total energy intake. Regarding breakfast, a cross-sectional study using 24-h dietary recall for two days reported that Brazilian adults who skipped breakfast at least 5 days/week had significantly higher total energy intake than those who did not [23]. Only a few cross-sectional studies reported an association between skipping dinner and total calorie intake. The National Health and Nutrition Examination Survey (NHANES) including 23,488 adults aged $\geq 18$ years in the US [24] and a crosssectional study including 275 nursing college students in Japan [25] showed an association between skipping dinner and low total energy intake. Differences in definitions of skipping breakfast/dinner, measurements of total calorie intake, and participants' characteristics might have contributed to the different associations between skipping breakfast/dinner and total energy intake in these previous studies. The effect of skipping dinner on total energy should be examined in more detail.

Another potential candidate for a link between skipping dinner and weight gain may be low diet quality. The NHANES showed that skipping dinner led to a deterioration in the healthy eating index (HEI) [24], the index used to measure diet quality that predicts CVD, cancer, and all-cause mortality [26]. The Multi-ethnic Study of Atherosclerosis (MESA) reported that the baseline HEI level was inversely associated with BMI 18 months after the baseline visit, suggesting that low diet quality was a risk factor for weight gain [27]. Among 
the components of HEI, skipping dinner significantly reduced intake of vegetables and seafood/plant proteins compared with skipping breakfast [24]. Because a recent systematic review clarified that low vegetable intake and fish intake were associated with weight gain [28], the greater impact of skipping dinner on weight gain may be due to the larger decrease in vegetable and seafood/plant protein intake compared with skipping breakfast. Chronotype may be another plausible factor contributing to the association between skipping dinner and weight gain. A Japanese cross-sectional study including 3304 mainly female university students showed that skipping dinner was more prevalent in female students who had a later sleep midpoint [29]. Because women with an evening chronotype are prone to weight gain [30], weight gain among university students who skipped dinner might be confounded by evening chronotype. Further studies are required to assess the mechanism underlying the association between skipping dinner and weight gain.

The present study has several limitations. Firstly, it included university students aged 18-19 years mainly at a single national university in Japan. The generalizability of our results should be assessed in different cohorts. Secondly, a dose-dependent association between dinner frequency and weight gain was not assessed, because dinner frequency was determined based on a simple question with only four possible answers: "Eating almost every day", "Skipping occasionally", "Skipping often", and "Usually skipping." After asking how many times students eat dinner per week strictly, the dose-dependent association between the frequency of dinner and weight gain should be assessed in more detail. Thirdly, the association between skipping dinner and weight gain may be confounded by unmeasured factors. For example, a previous cohort study suggested that depression modified the association between evening chronotype and weight gain [23]. Because individuals with an evening chronotype were prone to skipping dinner [23], depression may have also affected the association between skipping dinner and weight gain in this study. Perceived stress might be another potential confounder. A previous cross-sectional study reported that college students who skipped dinner had a higher level of perceived stress [31]. Because some longitudinal studies identified the perceived stress as a predictor of weight gain and obesity [32,33], the association of skipping dinner with weight gain and overweight/obesity was confounded by the perceived stress. Additionally, low physical activity might affect the association of skipping dinner with weight gain and overweight/obesity. Several cross-sectional studies reported that skipping dinner was associated with low physical activity $[14,34]$, which predicted weight gain and overweight/obesity $[35,36]$. The clinical impact of skipping dinner on weight gain and overweight/obesity should be examined in more well-designed studies. Fourthly, breakfast frequency was not associated with weight gain and overweight/obesity in the present study, contrary to the previous studies. One of the potential reasons for these conflicting results might be the shorter observation period ( $3.0 \pm 0.9$ years) of the present study than of the previous studies, including the Childhood Determinants of Adult Health (CDAH) study (5.0 \pm 0.3 years) [37], the Adventist Health Study 2 ( $7.4 \pm 1.2$ years) [38], the Health Professionals Follow-up study (10 years) [39], and the CARDIA study (18 years) [11]. The long-term impact of skipping dinner on weight gain and overweight/obesity should be verified. Short sleep duration might be another possible reason for no significant impact of skipping breakfast on weight gain and overweight/obesity. European and Brazilian cross-sectional studies suggested that skipping breakfast was associated with BMI in adolescents with sleep duration $\geq 8 \mathrm{~h} /$ day, whereas their association was blunted in those with sleep duration $<8 \mathrm{~h}[40]$. Because the present study included $2.4 \%$ male and $1.3 \%$ female students who had sleep duration $\geq 8 \mathrm{~h}$, skipping breakfast might not be associated with weight gain and overweight/obesity. Fifthly, a large number of students who skipped dinner $\geq$ occasionally over the past year of admission ate dinner almost every day during the observation period (Figure 4). Given that skipping dinner was associated with weight gain and overweight/obesity, this switching from skipping dinner $\geq$ occasionally to eating every day blunted the impact of skipping dinner. The true association of skipping dinner 
with weight gain and overweight/obesity might be stronger than that observed in the present study.

\section{Conclusions}

The present retrospective cohort study identified skipping dinner as a significant predictor of weight gain and overweight/obesity. These results suggest that dinner frequency may be a critical lifestyle factor for the prevention of obesity in addition to breakfast frequency. However, the clinical impact of dinner frequency should be clarified in further studies.

Supplementary Materials: The following are available online at https://www.mdpi.com/2072-664 3/13/1/271/s1, Table S1: Baseline characteristics, observation period, and outcome incidences of 17,573 male students stratified by breakfast frequency; Table S2: Baseline characteristics, observation period, and incidence of outcomes of 17,573 male students stratified by lunch frequency; Table S3: Baseline characteristics, observation period, and outcome incidences of 8860 female students stratified by breakfast frequency; Table S4: Baseline characteristics, observation period, and outcome incidences of 8860 female students stratified by lunch frequency; Table S5: Baseline characteristics of 212 male students with baseline dinner frequency of skipping $\geq$ occasionally who underwent annual health checkup 1 year after admission; Table S6: Baseline characteristics of 288 female students with baseline dinner frequency of skipping $\geq$ occasionally who underwent annual health checkup 1 year after admission; Figure S1: Annual health checkups during the observation period in the students admitted in April $(n=29,985)$ and October $(n=159)$.; Figure S2: Breakfast frequency and the cumulative probabilities of the incidence of weight gain $\geq 10 \%(a, b)$ and $B M I \geq 25 \mathrm{~kg} / \mathrm{m}^{2}(\mathrm{c}, \mathrm{d})$ in male $(\mathrm{a}, \mathrm{c})$ and female (b,d) students; Figure S3: Lunch frequency and the cumulative probabilities of the incidence of weight gain $\geq 10 \%(a, b)$ and BMI $\geq 25 \mathrm{~kg} / \mathrm{m}^{2}(\mathrm{c}, \mathrm{d})$ in male $(\mathrm{a}, \mathrm{c})$ and female $(\mathrm{b}, \mathrm{d})$ students.

Author Contributions: Conceptualization, R.Y. (Ryohei Yamamoto) and T.M.; data curation, R.Y. (Ryohei Yamamoto), K.N., S.I., I.N., M.N., K.Y.-T., T.K. and T.M.; formal analysis, R.Y. (Ryohei Yamamoto); writing—original draft, R.Y. (Ryohei Yamamoto) and R.T.; writing—review and editing, R.T., M.S., R.Y. (Ryuichi Yoshimura), and S.O.; and supervision, T.M. All authors have read and agreed to the published version of the manuscript.

Funding: This research received no external funding.

Institutional Review Board Statement: The study was conducted according to the guidelines of the Declaration of Helsinki, and approved by the Institutional Ethics Committee of Health and Counseling Center, Osaka University (No. 17 approved on 23 October 2020) and Osaka University Hospital (No. 18352 approved on 28 January 2019).

Informed Consent Statement: The present study used an opt-out approach to informed consent, according to Japanese Ethical Guidelines for Medical and Health Research Involving Human Subjects.

Data Availability Statement: The data presented in this study are available on request from the corresponding author. The data are not publicly available because they were not collected originally for researches.

Conflicts of Interest: The authors declare no conflict of interest.

\section{References}

1. Jayedi, A.; Rashidy-Pour, A.; Khorshidi, M.; Shab-Bidar, S. Body mass index, abdominal adiposity, weight gain and risk of developing hypertension: A systematic review and dose-response meta-analysis of more than 2.3 million participants. Obes. Rev. 2018, 19, 654-667. [CrossRef] [PubMed]

2. Vazquez, G.; Duval, S.; Jacobs, D.R.; Silventoinen, K. Comparison of body mass index, waist circumference, and waist/hip ratio in predicting incident diabetes: A meta-analysis. Epidemiol. Rev. 2007, 29, 115-128. [CrossRef] [PubMed]

3. Chen, Y.; Copeland, W.K.; Vedanthan, R.; Grant, E.; Lee, J.E.; Gu, D.; Gupta, P.C.; Ramadas, K.; Inoue, M.; Tsugane, S.; et al. Association between body mass index and cardiovascular disease mortality in east Asians and south Asians: Pooled analysis of prospective data from the Asia Cohort Consortium. BMJ 2013, 347, 1-19. [CrossRef] [PubMed]

4. Di Angelantonio, E.; Bhupathiraju, S.N.; Wormser, D.; Gao, P.; Kaptoge, S.; de Gonzalez, A.B.; Cairns, B.J.; Huxley, R.; Jackson, C.L.; Joshy, G.; et al. Body-mass index and all-cause mortality: Individual-participant-data meta-analysis of 239 prospective studies in four continents. Lancet 2016, 388, 776-786. [CrossRef] 
5. The, N.S.; Suchindran, C.; North, K.E.; Popkin, B.M.; Gordon-Larsen, P. Association of adolescent obesity with risk of severe obesity in adulthood. JAMA 2010, 304, 2042-2047. [CrossRef]

6. Wang, Z.; Peng, Y.; Liu, M. Age Variation in the Association Between Obesity and Mortality in Adults. Obesity 2017, 25, $2137-2141$. [CrossRef]

7. Brown, $\mathrm{C}$. The information trail of the "Freshman 15"-A systematic review of a health myth within the research and popular literature. Health Inf. Libr. J. 2008, 25, 1-12. [CrossRef]

8. Crombie, A.P.; Ilich, J.Z.; Dutton, G.R.; Panton, L.B.; Abood, D.A. The freshman weight gain phenomenon revisited. Nutr. Rev. 2009, 67, 83-94. [CrossRef]

9. St-Onge, M.P.; Ard, J.; Baskin, M.L.; Chiuve, S.E.; Johnson, H.M.; Kris-Etherton, P.; Varady, K. Meal Timing and Frequency: Implications for Cardiovascular Disease Prevention: A Scientific Statement from the American Heart Association. Circulation 2017, 135, e96-e121. [CrossRef]

10. Schoenfeld, B.J.; Aragon, A.A.; Krieger, J.W. Effects of meal frequency on weight loss and body composition: A meta-analysis. Nutr. Rev. 2015, 73, 69-82. [CrossRef]

11. Odegaard, A.O.; Jacobs, D.R.; Steffen, L.M.; Van Horn, L.; Ludwig, D.S.; Pereira, M.A. Breakfast frequency and development of metabolic risk. Diabetes Care 2013, 36, 3100-3106. [CrossRef] [PubMed]

12. Ma, X.; Chen, Q.; Pu, Y.; Guo, M.; Jiang, Z.; Huang, W.; Long, Y.; Xu, Y. Skipping breakfast is associated with overweight and obesity: A systematic review and meta-analysis. Obes. Res. Clin. Pract. 2020, 14, 1-8. [CrossRef]

13. Marín-Guerrero, A.C.; Gutiérrez-Fisac, J.L.; Guallar-Castillón, P.; Banegas, J.R.; Rodríguez-Artalejo, F. Eating behaviours and obesity in the adult population of Spain. Br. J. Nutr. 2008, 100, 1142-1148. [CrossRef] [PubMed]

14. Azadbakht, L.; Akbari, F.; Qorbani, M.; Esmaeil Motlagh, M.; Ardalan, G.; Heshmat, R.; Daneshzad, E.; Kelishadi, R. Dinner consumption and cardiovascular disease risk factors among a nationally representative sample of Iranian adolescents: The CASPIAN-III Study. J. Cardiovasc. Thorac. Res. 2019, 11, 138-146. [CrossRef] [PubMed]

15. McCrory, M.A. Meal skipping and variables related to energy balance in adults: A brief review, with emphasis on the breakfast meal. Physiol. Behav. 2014, 134, 51-54. [CrossRef]

16. Ford, C.; Chang, S.; Vitolins, M.Z.; Fenton, J.I.; Howard, B.V.; Rhee, J.J.; Stefanick, M.; Chen, B.; Snetselaar, L.; Urrutia, R.; et al. Evaluation of diet pattern and weight gain in postmenopausal women enrolled in the Women's Health Initiative Observational Study. Br. J. Nutr 2017, 117, 1189-1197. [CrossRef] [PubMed]

17. Hirko, K.A.; Kantor, E.D.; Cohen, S.S.; Blot, W.J.; Stampfer, M.J.; Signorello, L.B. Body mass index in young adulthood, obesity trajectory, and premature mortality. Am. J. Epidemiol. 2015, 182, 441-450. [CrossRef]

18. Wu, Y.; Zhai, L.; Zhang, D. Sleep duration and obesity among adults: A meta-analysis of prospective studies. Sleep Med. 2014, 15, 1456-1462. [CrossRef]

19. Okada, C.; Imano, H.; Muraki, I.; Yamada, K.; Iso, H. The Association of Having a Late Dinner or Bedtime Snack and Skipping Breakfast with Overweight in Japanese Women. J. Obes. 2019, 2019, 1-5. [CrossRef]

20. Klein, D. Implementing a General Framework for Assessing Interrater Agreement in Stata. Stata J. 2018, 18, 871-901. [CrossRef]

21. Koren, J.P.; Herta, J.; Fürbass, F.; Pirker, S.; Reiner-Deitemyer, V.; Riederer, F.; Flechsenhar, J.; Hartmann, M.; Kluge, T.; Baumgartner, C. Automated long-term EEG review: Fast and precise analysis in critical care patients. Front. Neurol. 2018, 9, 454. [CrossRef] [PubMed]

22. Pot, G.K.; Hardy, R.; Stephen, A.M. Irregularity of energy intake at meals: Prospective associations with the metabolic syndrome in adults of the 1946 British birth cohort. Br. J. Nutr. 2016, 115, 315-323. [CrossRef] [PubMed]

23. Batista-Jorge, G.C.; Barcala-Jorge, A.S.; Oliveira Dias, A.F.; Silveira, M.F.; De Farias Lelis, D.; Oliveira Andrade, J.M.; Claro, R.M.; De Paula, A.M.B.; Guimaraes, A.L.S.; Ferreira, A.V.; et al. Nutritional Status Associated to Skipping Breakfast in Brazilian Health Service Patients. Ann. Nutr. Metab. 2016, 69, 31-40. [CrossRef] [PubMed]

24. Zeballos, E.; Todd, J.E. The effects of skipping a meal on daily energy intake and diet quality. Public Health Nutr. 2020. [CrossRef] [PubMed]

25. Kuroda, T.; Onoe, Y.; Yoshikata, R.; Ohta, H. Relationship between skipping breakfast and bone mineral density in young Japanese women. Asia Pac. J. Clin. Nutr. 2013, 22, 583-589. [CrossRef]

26. Reedy, J.; Krebs-Smith, S.M.; Miller, P.E.; Liese, A.D.; Kahle, L.L.; Park, Y.; Subar, A.F. Higher diet quality is associated with decreased risk of all-cause, cardiovascular disease, and cancer mortality among older adults. J. Nutr. 2014, 144, 881-889. [CrossRef]

27. Gao, S.K.; Beresford, S.A.A.; Frank, L.L.; Schreiner, P.J.; Burke, G.L.; Fitzpatrick, A.L. Modifications to the healthy eating index and its ability to predict obesity: The multi-ethnic study of atherosclerosis. Am. J. Clin. Nutr. 2008, 88, 64-69. [CrossRef]

28. Schlesinger, S.; Neuenschwander, M.; Schwedhelm, C.; Hoffmann, G.; Bechthold, A.; Boeing, H.; Schwingshackl, L. Food Groups and Risk of Overweight, Obesity, and Weight Gain: A Systematic Review and Dose-Response Meta-Analysis of Prospective Studies. Adv. Nutr. 2019, 10, 205-218. [CrossRef]

29. Sato-Mito, N.; Sasaki, S.; Murakami, K.; Okubo, H.; Takahashi, Y.; Shibata, S.; Yamada, K.; Sato, K. The midpoint of sleep is associated with dietary intake and dietary behavior among young Japanese women. Sleep Med. 2011, 12, 289-294. [CrossRef]

30. Maukonen, M.; Kanerva, N.; Partonen, T.; Männistö, S. Chronotype and energy intake timing in relation to changes in anthropometrics: A 7-year follow-up study in adults. Chronobiol. Int. 2019, 36, 27-41. [CrossRef] 
31. Pelletier, J.E.; Lytle, L.A.; Laska, M.N. Stress, Health Risk Behaviors, and Weight Status Among Community College Students. Health Educ. Behav. 2015, 43, 139-144. [CrossRef] [PubMed]

32. Fowler-Brown, A.G.; Bennett, G.G.; Goodman, M.S.; Wee, C.C.; Corbie-Smith, G.M.; James, S.A. Psychosocial stress and 13-year BMI change among blacks: The pitt county study. Obesity 2009, 17, 2106-2109. [CrossRef] [PubMed]

33. Mouchacca, J.; Abbott, G.R.; Ball, K. Associations between psychological stress, eating, physical activity, sedentary behaviours and body weight among women: A longitudinal study. BMC Public Health 2013, 13. [CrossRef] [PubMed]

34. Lim, H.-S.; Yoo, J.-J. Association between Health Indicators and Health-Related Quality of Life according to Physical Activity of Older Women. Healthcare 2020, 8, 507. [CrossRef] [PubMed]

35. Littman, A.J.; Kristal, A.R.; White, E. Effects of physical activity intensity, frequency, and activity type on 10-y weight change in middle-aged men and women. Int J. Obes. 2005, 29, 524-533. [CrossRef] [PubMed]

36. Wagner, A.; Simon, C.; Ducimetière, P.; Montaye, M.; Bongard, V.; Yarnell, J.; Bingham, A.; Hedelin, G.; Amouyel, P.; Ferrières, J.; et al. Leisure-time physical activity and regular walking or cycling to work are associated with adiposity and $5 \mathrm{y}$ weight gain in middle-aged men: The PRIME Study. Int J. Obes. 2001, 25, 940-948. [CrossRef] [PubMed]

37. Smith, K.J.; Gall, S.L.; McNaughton, S.A.; Cleland, V.J.; Otahal, P.; Dwyer, T.; Venn, A.J. Lifestyle behaviours associated with 5-year weight gain in a prospective cohort of Australian adults aged 26-36 years at baseline. BMC Public Health 2017, 17, 54. [CrossRef]

38. Kahleova, H.; Lloren, J.I.; Mashchak, A.; Hill, M.; Fraser, G.E. Meal Frequency and Timing Are Associated with Changes in Body Mass Index in Adventist Health Study 2. J. Nutr. 2017, 147, 1722-1728. [CrossRef]

39. van der Heijden, A.A.W.A.; Hu, F.B.; Rimm, E.B.; van Dam, R.M. A Prospective Study of Breakfast Consumption and Weight Gain among U.S. Men. Obesity 2007, 15, 2463-2469. [CrossRef]

40. Forkert, E.C.O.; De Moraes, A.C.F.; Carvalho, H.B.; Manios, Y.; Widhalm, K.; González-Gross, M.; Gutierrez, A.; Kafatos, A.; Censi, L.; De Henauw, S.; et al. Skipping breakfast is associated with adiposity markers especially when sleep time is adequate in adolescents. Sci. Rep. 2019, 9, 1-10. [CrossRef] 